\title{
FALSE POSITION OF THE POSTERIOR POLE AS A FUNDUS LANDMARK*
}

BY

\author{
JAMES FISON
}

Harrogate

A CENTURY and a half has passed since the appearance of the "posterior pole" as a landmark in the fundus, but the confusion among anatomists started by Soemmerring's essay on the "Yellow Spot" (Soemmerring, 1799) still shows no sign of clearing. An attempt was made some years ago to clarify the position in a short preliminary paper (Fison, 1920). Nevertheless, many writers of text-books are still led astray into using the term "posterior pole" as a landmark from which measurements can be made. Wolff $(1948,1954)$ used the term " posterior pole" in this way and, moreover, seemed to regard the distance between fovea and disc in the vertical plane as being almost negligible. Paul Bonnet, who, as professor of ophthalmology at Lyons, collaborated with A. Latarjet in the revision of the article on the eye in Testut's text-book (Testut and Latarjet, 1949), clearly believes in the tradition handed down from Soemmerring that the fovea is the undoubted locus of the "posterior pole"; it must be presumed that he accepts all Testut's statements since 1922 about the disc, macula, and " posterior pole" (Testut, 1922, 1930).

The fictitious use of the "posterior pole" as a measuring point may be found in most of the well-known text-books of human anatomy, e.g. Gray with his various recent editors $(1858,1866,1901,1905,1909,1918$, 1949), Testut $(1894,1899,1922,1930)$ and Testut and Latarjet (1949), Buchanan with his editor Wood Jones (1914, 1949), Cunningham with his editor Robinson, and later Brash and Jamieson (1902, 1915, 1922, 1931, 1937, 1951), and Rouvière with his editor Cordier $(1924,1954)$. From all these one might conclude that the " posterior pole " was the most important landmark in the fundus, so great is the significance of measuring from it made to appear. In fact it has no proved locus in the fundus, though there seems at times to be a peculiar desire to relate the positions of the only true and visible landmarks, the optic disc and macula, to one another through the medium of the imaginary "posterior pole". How this fictitious landmark is to be found and recognized is never disclosed, except in the vaguest possible way by Salzmann (1912). Circumlocution makes it tiresome, and sometimes difficult, to be sure of the relation of disc and macula to one another, as for example in Quain's " Elements of Anatomy" (Quain, 1909), in its day one of the best English text-books. So long as it was firmly believed, as is still the case with

* Received for publication July 22, 1955. 
Testut, Buchanan, and Rouvière (and their editors), that fovea and " posterior pole" had a common locus (in all of them the distance between the levels of fovea and disc is given firmly as $1 \mathrm{~mm}$.), this use of the " posterior pole" as an intermediary did not much matter, though it seemed unnecessary and looked pedantic. Some uncertainty about the distance between the levels of the fovea and disc becomes evident, however, as soon as the loci of the fovea and pole are divorced. No definite figure for this distance is now given by the modern editors of Gray and Cunningham, or by Wolff, and the relation of fovea to disc in the vertical plane is not mentioned at all in the first two books.

There is no unanimity about the disc-" posterior pole" relationship in the vertical plane. In some books the disc is described as below the pole, and in others above. Even Testut (7th edition, 1922), when in the fullness of time (28 years after his first edition in 1894) he decided that all the false statements about the macula-disc relationship, together with the false pictures, ought to be radically altered, changed them without comment. It will no doubt be recalled by some that this involved raising the locus of the disc $2 \mathrm{~mm}$., from a position $1 \mathrm{~mm}$. below the level of the "posterior pole" to a new position $1 \mathrm{~mm}$. above it. In spite of Testut's example, all these false, discarded statements came back into circulation 2 years later in a new text-book by Rouvière (1924), and are still to be found in the latest edition revised by $G$. Cordier (Rouvière, 1954). The author of the article on the eye in "Cunningham's Anatomy" (ed. J. C. Brash, 1951) was the first to give a reason for such a change in the disc-"posterior pole" relationship, and, in so doing, he demonstrated that there were no anatomical grounds for the use of the "posterior pole" as a landmark in the fundus. The change consisted in moving the disc upwards from a position slightly below the pole to one slightly above it, and the reason given was that $H$. $M$. Traquair had called the author's attention to an experiment concerning the blind spot and fixation point. Anatomical considerations did not enter into this experiment, which was purely physiological, and the reason, therefore, was not well founded, since the " posterior pole" was not involved in the experiment in any way.

The effect of the misuse of the " posterior pole" as a landmark has perhaps been most pernicious in the teaching about the axes of the eye. It is obvious that, once the "posterior pole" and fovea are presumed to have the same locus, the teaching of Helmholtz about the fundamental difference between the axis oculi and the visual axis becomes meaningless. Yet the statement by Helmholtz (1867) remained unchanged when his "Handbuch" was edited by Nagel, Gullstrand, and von Kries (Helmholtz, 3rd ed., 1909-11). Such differences between the axes of the eye are frankly ignored, even in the recent editions of Gray, Cunningham, Buchanan, and Testut.

Soemmerring's essay on the "Yellow Spot" is undoubtedly responsible for these fallacies. The fervour of his language, the constant tiresome reiteration of the importance of his discovery of the marvellous small 
central foramen with the yellow border, the exuberance of imagination engendered by this discovery leading to descriptions of dissections so amazing in conception as to be incredible in execution; and lastly an imaginary debate between the author and the physiologist Haller, the whole essay ending in eccentric anticipations and fantasies-all this implanted firmly in the minds of succeeding generations the strong tradition that the little "hole" in the centre of the "Yellow Spot" was the true centre of the posterior scleral segment, and, at the same time, the cause of the blind spot. This myth, at least in part, still seems to be embedded in the minds of most anatomists, who ignore the lack of credentials of the " posterior pole ".

\section{Personal Investigations}

I became interested in the problem of the " posterior pole" in 1916 when, during the examination of the eye of a rating at the Royal Naval Hospital, Chatham, I saw that the centre of the disc was distinctly below the level of the macula. Re-examination under a mydriatic confirmed this observation and also the fact that there was nothing else abnormal about the eye (Fison, 1920). While recognizing the remarkably high position of the macula, I had, of course, no idea how rare this actually was, but it was enough to start a habit of looking for unusual positions of the macula. I could find no reference to anything of the sort in contemporary text-books of anatomy, and references to the relative positions of the macula and the disc, particularly as regards their relative levels, were usually scanty or inaccurate.

My personal observations of the relative levels, over nearly 40 years, have led to the following conclusions:

(1) The commonest position for the fovea is about on a level with the lower margin of the disc, but it is very often found above or below this point.

(2) The highest position observed was that already recorded, where the centre of the disc was described as being below the level of the macula. Here was an instance of the macular reflex not being visible, and the " macula" referred to was the small dark red spot at the centre of the macula proper (the zentraler roter Fleck of Fuchs, 1921) of about one-quarter of the diameter of the disc. The fovea, therefore, was about one-eighth of the diameter of the disc above the disc centre.

(3) The lowest position observed was noted on one of the comparatively rare occasions when the macular reflex was well seen and its highest point was below the level of the lower margin of the disc. The difference in levels between the fovea and the centre of the disc in this eye was estimated to be about $1 \frac{1}{8}$ disc diameters. Illustrations of such low positions occur in one of Oeller's Atlases.

Therefore, the variation in position of the fovea relative to the centre of the disc in the vertical plane can be stated to be about $1 \frac{1}{4}$ disc diameters, which is considerably greater than has hitherto been thought to be the case.

An important fact follows from this. Latarjet, Rouvière, and all who 
hold that the fovea and "posterior pole" have the same locus, are committed by implication to the belief that it is the optic disc and not the macula which changes its position in the fundus. Now this, though absolute proof is lacking, must surely be extremely unlikely in view of the very much greater age and importance of the optic nerve, in comparison with which the macula is a phylogenetic upstart. In any case, the mere fact of its uncertain position makes the fovea unsuitable as the locus for the " posterior pole".

There are two essential difficulties in finding a locus for the "posterior pole".

First, two definitions of the " posterior pole" are current: there are cogent reasons for thinking that, if the indications of Salzmann (1912) are followed in seeking the locus of the pole, two loci will be the result.

Secondly, the modern view of the shape of the eye, which is, in its simplest form, an irregular oblate spheroid, rather flattened from above downwards, and bulging somewhat backwards and outwards in its temporal half, may discourage further attempts at locating the position of the " posterior pole" in the fundus.

\section{Summary}

Attention is called to a long-standing confusion in articles on the eye in modern text-books of human anatomy, which has existed since Soemmerring's day and is due to the strong tradition, which he started, that the fovea and the anatomical "posterior pole" have the same locus. An attempt to substitute physiological experiment for the absence of anatomical fact proved unsuccessful. Reference to the "posterior pole" as an anatomical entity must be dropped.

\section{REFERENCES}

Buchanan, A. M. (1914). “ "Manual of Anatomy ”, 2nd impression, p. 1383. Baillière, Tindall and Cox, London.

(1949). "Buchanan's Manual of Anatomy", 8th ed., ed. F. Wood Jones, p. 1495. Baillière, Tindall and Cox, London.

Cunningham, D. J. (1902). "Text-book of Anatomy", 1st ed., pp. 682, 689. Pentland, Edinburgh.

(1915). “Cunningham's Text-book of Anatomy ", 4th ed. rev., ed. A. Robinson, pp. 807, 815. Frowde and Hodder and Stoughton, London.

(1922). Ibid., 5th ed., ed. A. Robinson, pp. 801, 809. Frowde and Hodder and Stoughton, London.

(1931). Ibid., 6th ed., ed. A. Robinson, p. 810. Oxford University Press, London.

(1937). Ibid., 7th ed., ed. J. C. Brash and E. B. Jamieson, p. 1081. Oxford University Press, London.

(1951). Ibid., 9th ed., ed. J. C. Brash, pp. 1013, 1014, 1160, 1162, 1169. Oxford University London.

Fison, J. (1920). J. Anat. (Lond), 54, 184.

FuchS, E. (1921). "Lehrbuch der Augenheilkunde", 13th ed., p. 88. Deuticke, Vienna.

GraY, H. (1858). " "Anatomy, Descriptive and Surgical ", 1st ed., p. 560. Parker, London. (1866). Ibid., 4th ed., p. 592. Longmans, Green and Co., London.

(1901). Ibid., 15th ed., ed. T. Pickering Pick and R. Howden, p. 806. Longmans, Green, London.

(1905). Ibid., 16th ed., ed. T. Pickering Pick and R. Howden, p. 964. Longmans, Green,

London.? "(1909). "Anatomy, Descriptive and Applied", 17th ed., ed. R. Howden, p. 1011.

Longmans, Green, London. 
Gray, H. (1918). Ibid., 20th ed., ed. R. Howden, p. 961. Longmans, Green and Co., London. (1949). "Gray's Anatomy, Descriptive and Applied ", 30th ed., ed. T. B. Johnston and J. Whillis, p. 1193. Longmans, Green, London.

Helmholtz, H. voN (1867). "Handbuch der physiologischen Optik", p. 70 . (“Allgemeine Encyklopädie der Physik”, ed. G. Karsten, vol. 9). Voss, Leipzig.

(1909-11). Ibid., 3rd ed., ed. W. Nagel, A. Gullstrand, and J. von Kries, vol. 1, p. 78. Voss, Hamburg and Leipzig.

OelleR, J. (1896-1899). “Atlas der Ophthalmoskopie", vols A and B. Bergmann, Wiesbaden. QUAIN, J. (1909). " Elements of Anatomy", 11th ed., vol. 3, pt. 2, pp. 225, 226. Longmans, Green, London.

Rouvière, H. (1924). “Anatomie humaine, descriptive et topographique ", 1st ed., vol. 1, pp. 290, 298. Masson, Paris.

(1954). Ibid., 7th ed., rev. G. Cordier, vol. 1, pp. 315, 323. Masson, Paris.

SalzmanN, M. (1912). "Anatomie und Histologie des menschlichen Augapfels im Normalzustande ", p. 5. Deuticke, Leipzig.

Soemmerring, S. T. (1799). Commentationes Societatis Regiae Scientiarum Gottingensis, $13,3$.

TESTUT, L. (1894). “Traité d'anatomie humaine ", 1st and 2nd ed., vol. 3, pp. 118, 123, 157, 172, 174. Doin, Paris. (1899). Ibid., 4th ed., vol. 3, pp. 387, 393, 426, 443, 444. Doin, Paris. (1922). Ibid., 7th ed., vol. 3, pp. 424, 428, 468. Doin, Paris. (1930). Ibid., 8th ed.. rev. A. Latarjet, vol. 3, p. 601. Doin, Paris.

and LATARJE, A. (1949). Ibid., 9th ed., vol. 3, pp. 579, 619, 620, 627. Doin, Paris.

Wolff, E. (1948). "The Anatomy of the Eye and Orbit ", 3rd ed., pp. 38, 76, 100. Lewis, London. (1954). Ibid., 4th ed., pp. 41, 88, 114. Lewis, London. 